\title{
Recycling or Remarketing: Optimal Strategies for Outsourcing Remanufacturing
}

\author{
Feng Zhang1,2, Hong Chen ${ }^{1}$ \\ ${ }^{1}$ School of Management and Economics, University of Electronic Science and Technology of China, Chengdu, China \\ ${ }^{2}$ Business School, Guilin University of Electronic Technology, Guilin, China \\ Email: zzovxh@163.com
}

How to cite this paper: Zhang, F., \& Chen, H. (2020). Recycling or Remarketing: Optimal Strategies for Outsourcing Remanufacturing. Open Journal of Social Sciences, 8, 497-506. https://doi.org/10.4236/jss.2020.83042

Received: March 14, 2020

Accepted: March 28, 2020

Published: March 31, 2020

\begin{abstract}
Remanufacturing outsourcing creates the cannibalisation for the original equipment manufacturers' (OEMs') new products sales. In dealing with the cannibalization from the third-party remanufacturer (3PR), many OEMs such as ATK, Canada Engines, Ford and Land Rover, undertake used cores collecting or remanufactured products remarketing. Motivated by examples from industry, we develop two models in which an OEM produces new products but outsources remanufacturing operations to a 3PR according to two potential strategies in dealing with the cannibalization from remanufactured products: 1) collecting used cores from consumers or 2) remarketing all remanufactured products to consumers. Among other results, we find that, if the collection cost coefficient is not pronounced, the OEM would prefer remarketing remanufactured products than undertaking used cores collection, though the former creates fiercer cannibalization problems for new products sales. Further, as the collection cost coefficient is moderate, remarketing remanufactured products can create a win-win result for both parties. As such, we suggest that, practicing managers should focus both on the cost of collecting used cores and the cannibalisation problems of remanufacturing. This complements existing results which show that when remanufacturing is outsourced, the OEM equate minimising cannibalisation with maximizing profits.
\end{abstract}

\section{Keywords}

Remanufacturing Outsourcing, Recycling, Remarking, Cannibalization

\section{Introduction}

Cannibalisation problems are perhaps one of the most common business issues that marketing managers need to confront (Kotler \& Keller, 2012). They can oc- 
cur in markets with consumer heterogeneity on product quality, where lower-quality products can potentially cannibalise sales of higher-quality products (Desai, 2001). The cannibalisation problem is even more noticeable when OEMs outsource their remanufacturing operations to third-party remanufacturers (3PRs) because this usually opens a second, profitable, remanufactured goods market that is not directly controlled by OEMs. According to a comprehensive survey of the USA remanufacturing industry, only $6 \%$ of more than 2000 remanufacturing enterprises were OEMs (Hauser \& Lund, 2008). Given the size and growth of 3PRs, OEMs can no longer ignore the potential for cannibalisation of new product sales by remanufactured product sales (Oraiopoulos et al., 2012).

In dealing with the cannibalisation problems stemming from 3PR remanufactured products, many brand-name OEMs have taken one of two strategies. First, although many OEMs have outsourced remanufacturing to 3PRs, they still participate in remanufacturing operations by collecting used products, which act as cores for remanufacturing. For example, ATK, Canada Engines and Ford purchased several automotive salvage yards and parts recycling companies in North America and Europe through which they collect end-of-life vehicles from users and sell cores to 3PRs (Karakayali et al., 2007). Second, many other OEMs minimise the cannibalisation problems caused by $3 \mathrm{PR}$ remanufactured products by remarketing the remanufactured products. For instance, Land Rover has signed a memorandum of understanding in which Caterpillar Remanufacturing Services is a preferred supplier for Land Rover's remanufacturing products, while Land Rover offers an integrated distribution system for the remarketing of remanufactured products (Channel, 2017).

Based on the above motivations, we develop two models in which an OEM produces new products but outsources its remanufacturing operations to a $3 \mathrm{PR}$ with two possible options for dealing with cannibalisation problems caused by remanufacturing: 1) Participation in remanufacturing operations by collecting cores from consumers (Model $\mathrm{T}$ ) or 2) participating in remanufacturing operations by remarketing all remanufactured products to consumers (Model R). Using these two models, we intend to address the following questions.

How do the different options for mitigating cannibalisation effects affect all parties' optimal equilibriums?

From a profit-maximisation perspective, which is better for the manufacturer, 3PR and the overall industry?

The main contribution of this paper is twofold. First, there are numerous studies addressing issues related to cannibalisation problems in remanufacturing outsourcing, including (Debo et al., 2005, Ferguson \& Toktay, 2006, Oraiopoulos et al., 2012, Wang et al., 2017); however, none have paid attention to how different strategies undertaken by OEMs affect cannibalisation effects from 3PR remanufacturing. So, we complement these studies by highlighting such strategic choices. Second, although the question of whether OEMs should participate in reverse and/or remarketing operations has been well studied in the remanufacturing literature (see, e.g., Ferguson \& Toktay, 2006, Oraiopoulos et al., 2012, 
Zou et al., 2016), little attention has been paid to how should the OEMs should choose different strategies, when confronting cannibalisation problems caused by $3 \mathrm{PR}$ remanufacturing. In this paper, we analyse the importance of managing reverse or remarketing channels in controlling 3PR remanufacturing cannibalisation problems, then go a step further to compare the economic implications of two potential management strategies.

The rest of the paper is organised as follows. Section 2 describes both models and analyses their optimal decisions. Sections 3 and 4 examine both models and present the main results. Section 5 concludes our work and provides future research directions.

\section{Model Description and Assumptions}

The primary goal of this paper is to understand how decisions regarding used core collection and remanufactured product remarketing are made by OEMs and their effects on economic factors. As shown in Figure 1, we consider that an OEM has two possible options when dealing with cannibalisation problems arising from 3PR remanufacturing: 1) Participating in remanufacturing operations by collecting cores from consumers and selling them to the 3PR (Model T) or 2) participating in remanufacturing operations by purchasing all remanufactured products from the $3 \mathrm{PR}$ and remarketing them to consumers (Model R). We discuss and lay out our key assumptions below.

We make several assumptions, as follows.

Assumption 1. The unit cost of remanufacturing a used core $\left(c_{r}\right)$ is lower than that of producing a new product $\left(c_{n}\right)$; i.e., $c_{r}<c_{n}$.

Prior literature affirms that companies can save $40 \%-65 \%$ in manufacturing costs through remanufacturing (Giutini \& Gaudette, 2003). That is because remanufacturing can effectively reduce procurement costs by reusing some components and parts (Zou et al., 2016). This assumption is widespread in the supply chain literature (Ferguson \& Souza, 2010, Xiong et al., 2013, Yan et al., 2015; Chai et al., 2019).

Assumption 2. Consumer willingness-to-pay for a new product is heterogeneous and uniformly distributed in the interval $[0,1]$. For each consumer, the ratio of the willingness-to-pay for a remanufactured product to that for a new product is $\gamma(0 \leq \gamma \leq 1)$.

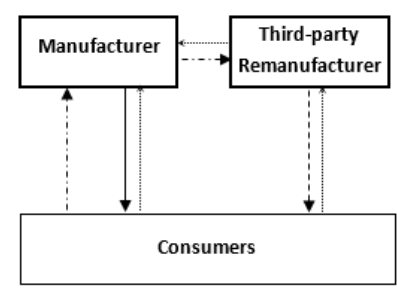

(a) Model T

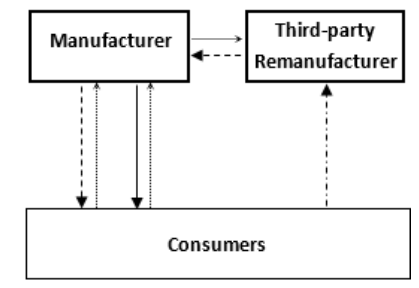

(b) Model $\mathrm{R}$

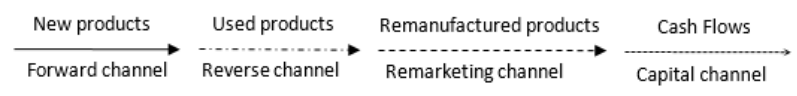

Figure 1. Two basic models. 
Assumption 2 represents a vertical differentiation model, which allows for heterogeneity in individual consumers' willingness-to-pay for quality; i.e., all consumer willingness-to-pay for remanufactured products is lower than that for new products (Debo et al., 2010, Xiong et al., 2013, Zou et al., 2016). Note that such heterogeneity in willingness-to-pay for new and remanufactured products is supported by empirical evidence (Majumder \& Groenevelt, 2001, Marion, 2004, Guide Jr. \& Li, 2010, Agrawal et al., 2012, Subramanian \& Subramanyam, 2013).

Assumption 3. The market size of the consumer population is assumed to not change over time and is normalised to 1 .

Assumption 3 is widely accepted in remanufacturing research (see, e.g., (Savaskan et al., 2004, Ferguson \& Souza, 2010, Xiong et al., 2013, Örsdemir et al., 2014, Yan et al., 2015, Wang et al., 2017).

Based on Assumptions 2 - 3, we can derive inverse demand functions for new and remanufactured products as follows:

$$
\begin{gathered}
p_{n}=1-q_{n}-\gamma q_{r} \\
p_{r}=\gamma\left(1-q_{n}-q_{r}\right)
\end{gathered}
$$

We should note that consumers usually discount the value of remanufactured products, which creates the problem of cannibalisation between new and remanufactured products (Yan et al. 2015). For example, consumers will not purchase remanufactured products if $\gamma=0$, because they regard them to be of lower quality than new ones. However, if $\gamma=1$, consumers are willing to pay the same amount for remanufactured and new products.

Assumption 4. Without loss of generality, we assume a collection cost function of $\frac{1}{2} k q_{r}^{2}$, where $\mathrm{k}$ is a scaling parameter.

We borrow this assumption from previous literature (Ferguson and Toktay 2010, Jacobs and Subramanian 2012, Atasu and Souza 2013, Zou et al. 2016). It means that additional effort is required to recover larger volumes, due to the fact that the cost of collecting used products increases non-linearly with the quantity collected (Zou et al. 2016).

Assumption 5. All decisions are considered in a single-period setting in both models.

We focus on the average supply chain profit per period, as (Savaskan et al. 2004) assumed that the product existed in the market previously and can be returned to the OEM for reuse. This approach enables us to focus on steady-state profits, facilitates analytical tractability in our model, and contributes to the solution of our problems. All relevant variables are defined in Table 1.

\section{Model Formulation and Solution}

In this section, we analyse two remanufacturing models: Model T and Model R. Variable $\Pi_{x}^{i}$ refers to the profits for player $i$ under Model $j$. Subscript $i \in\{m, 3 p, t\}$ denotes the players of the OEM, 3PR and total supply chain, respectively; while superscript $j \in\{T, R\}$ denotes Model T and Model R, respectively. 
Table 1. Variables and definitions.

\begin{tabular}{cc}
\hline Variables & Definitions \\
\hline$\gamma$ & Consumer value discount for remanufactured products \\
$c_{n} / c_{r}$ & Unit production cost of a new/remanufactured component \\
$k$ & Scaling parameter \\
$p_{n}^{i} / p_{r}^{i}$ & Price of new/remanufactured product in Model $i, \quad i \in(T, R)$ \\
$q_{n}^{i} / q_{r}^{i}$ & Quantity of new/remanufactured products in Model $i, i \in(T, R)$ \\
$f$ & Remanufacturing patent license fees in Model T \\
$w$ & Wholesale price of new component in Model R \\
$\Pi_{x}^{i}$ & Player $x^{\prime}$ s profit in Model $i, \quad x \in(m, 3 p, t), i \in(T, R)$ \\
\hline
\end{tabular}

\subsection{Model T}

The sequence of events for Model T is as follows: First, the OEM announces a patent license fee per remanufactured product; i.e., $f^{T}$. Sequentially, both the OEM and the 3PR determine the optimal quantities of new and remanufactured products, respectively. Then, the OEM and 3PR problems are as follows, respectively:

$$
\begin{gathered}
\max _{q_{n}, f} \Pi_{m}^{T}=\left(p_{n}-c_{n}\right) q_{n}+f q_{r}-\frac{1}{2} k q_{r}^{2} \\
\max _{q_{r}} \Pi_{3 p}^{T}=\left(p_{r}-c_{r}\right) q_{r}-f q_{r}
\end{gathered}
$$

We solve the problem with backward induction to determine the subgame perfect equilibrium and present the equilibrium decisions and profits in Table 2 (for clarity, all proofs are provided in the appendix).

\subsection{Model R}

The sequence of events in Model $\mathrm{R}$ is as follows: First, the 3PR determines the wholesale price of remanufactured products sold to the OEM, $w_{r}^{R}$, who responds with the optimal quantities of both products (i.e., $q_{n}, q_{r}$ ). Then, both parties' problems are as follows.

$$
\begin{array}{r}
\max _{q_{n}, q_{r}} \Pi_{m}^{R}=\left(p_{n}-c_{n}\right) q_{n}+\left(p_{r}-w\right) q_{r} \\
\max _{w_{r}} \Pi_{3 p}^{R}=\left(w-c_{r}\right) q_{r}-\frac{1}{2} k q_{r}^{2}
\end{array}
$$

Using backward induction again, we can summarise all the equilibrium decisions in Table 2.

To enable comparison of the interior point solutions to both models, i.e., $0<q_{r}<q_{n}$, as per (Xiong et al. 2013) and (Yan et al. 2015), we make the following assumption:

Assumption 6. In both our models, the cost of remanufacturing a core is not sufficiently small or large; that is, $\frac{-k+c_{n} k-4 \gamma+6 c_{n} \gamma+4 \gamma^{2}-2 c_{n} \gamma^{2}}{2+2 \gamma}<c<c_{n} \gamma$. 
Table 2. Equilibrium decisions and profits.

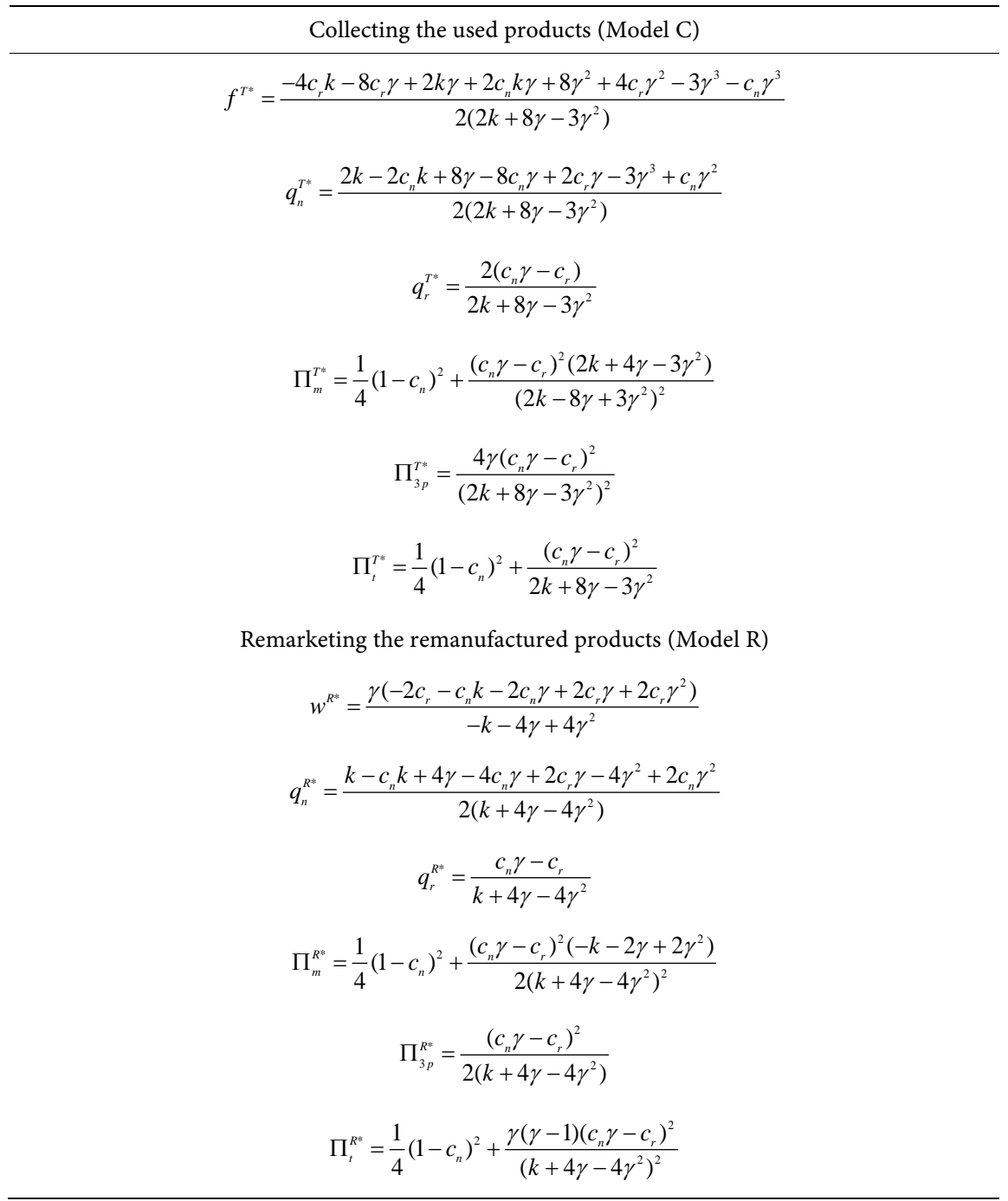

\section{Analysis}

In this section, we start by comparing the equilibrium decisions of the two models. Subsequently, we enrich our analysis by exploring the relative profitability outcomes of both models.

Proposition 1: 1) The optimal quantities of remanufactured products in Model $\mathrm{R}$ are higher than those in Model T; essentially: $q_{r}^{T^{*}}<q_{r}^{R^{*}}$;

2) The OEM is less likely to provide greater quantities of new products in Model R than in Model T; essentially: $q_{n}^{T^{*}}>q_{n}^{R^{*}}$.

Prior to explaining Proposition 1, we briefly examine the OEM's position in both models. In Model T, the OEM collects used cores and sells them to the 3PR. As such, the OEM acts as a Stackelberg leader. In Model R, the OEM is a downstream agent who sets optimal quantities of remanufactured products according to the wholesale price set by the 3PR. Thus, Proposition 1 (1) reveals that, compared to Model R, collecting used cores according to Model T places the OEM in an advantageous position for dealing with the cannibalisation problem in rema- 
nufacturing outsourcing. That is, when confronting cannibalisation caused by 3PR remanufacturing, the OEM can charge a higher patent license fee per remanufactured unit, which results in lower quantities being available in the market. However, since the 3PR cares nothing about the potential cannibalisation of new product sales due to remanufactured products in Model R, it usually sets a lower wholesale price to induce the OEM to sell higher quantities of remanufactured products.

Proposition 2. When the used core collection cost is relative high, i.e., $k>k_{1}$, the equilibrium profit of the OEM is greater in Model $\mathrm{T}$ than in Model R (i.e., $\left.\Pi_{M}^{T^{*}}>\Pi_{M}^{R^{*}}\right)$, otherwise, the opposite is true.

As mentioned earlier, unlike the 3PR, the OEM cares greatly about the cannibalisation problem caused by remanufacturing. When $k>k_{1}$, the collection cost is relatively high and the OEM would naturally increase the wholesale price of used cores. An increase in the wholesale price of remanufactured products is associated with a decrease in the optimal quantities of remanufactured products. Furthermore, the less remanufactured product available, the higher potential market and marginal revenue from new products sales. As such, when $k>k_{1}$, the OEM's profitability from new product sales is so high that it "compensates" for the profit "lost" in used core wholesaling because there are fewer remanufactured products "competing" with new products and weaker cannibalisation due to remanufacturing. However, when the used core collection cost is not pronounced, i.e., $k<k_{1}$, compared to remarketing remanufactured products, collecting used cores hurts the OEM's profits due to the more remanufactured products available from the market, the fiercer cannibalization effects of new products sales by remanufactured products.

Proposition 3. The equilibrium profit of the 3PR estimated by Model $\mathrm{T}$ is always lower than that of Model R, i.e., $\Pi_{3 P}^{T^{*}}<\Pi_{3 P}^{R^{*}}$.

In both models, the OEM has two main tasks: 1) to maximize its profitability and 2) to limit the adverse effects of cannibalization problem from the remanufacturer. It should be noted that, in Model T, OEMs undertake core collection, giving them the role of Stackelberg leaders who care greatly about cannibalisation between both products. As a result, when the OEMs would set a relative higher commission fees to the 3PR. However, in Model R, the OEMs undertake remanufactured product remarketing. In this scenario, the OEMs' optimal units for remanufactured products are impacted by the 3PR, who cares nothing about the potential cannibalisation of new product sales and sets a lower wholesale price for remanufactured products. That is, in Model T, the 3PR acts as a Stackelberg leader and the wholesale price premium not only offsets the advantage of new product marketing but can also gains much greater profitability from remanufacturing.

Proposition 4. The equilibrium profit of the industry is always lower in Model T than in Model R; that is: $\Pi_{T}^{T^{*}}<\Pi_{T}^{R^{*}}$.

Proposition 4 indicates that the total profits in the closed-loop supply channel are always lower when the OEM collects used cores than when it remarkets re- 
manufactured products. It is noted that the OEM benefits more in Model T (see Proposition 2), while the 3PR benefits more in Model R (see Proposition 3). As such, Proposition 4 suggests that the increase in the OEM's profitability is so limited that it cannot "compensate" for the 3PR's profit "loss". although the OEM would benefit more from the strategy of used cores collection, such strategic choice would always be detrimental to the $3 \mathrm{PR}$ and the overall industry.

\section{Discussion and Conclusion}

In this paper, motivated by examples from industry, we developed two models in which an OEM produces new products and outsources remanufacturing operations to a 3PR with two possible strategies for dealing with cannibalisation problems arising from remanufacturing: 1) Participating in remanufacturing operations by collecting cores from consumers (Model T) or 2) participating in remanufacturing operations by remarketing remanufactured products to consumers (Model R). Our analysis reveals the implications for practicing managers as below.

Based on Propositions 1, we can conclude that compared to remarketing remanufactured products, collecting used cores is more efficient way for the OEM to deal with the cannibalization problems. This argument is partly consistent with the results of (Guide Jr and Li 2010) who argue that, although annual returns of used products in excess of $\$ 800$ million, a leading networking equipment manufacturer scraps almost all of their product returns instead of remanufacturing due to a fear of new product sales cannibalization. From a profit-maximisation perspective, which is better for the manufacturer, 3PR and the overall industry? Surprisingly, Proposition 2 indicates that the scaling parameter of collection cost plays an important role in dealing with the cannibalization problems and determining the OEM profit estimates of the two models. As such, we suggest that, practicing managers should not only focus on the collecting cost of used cores, but also should pay attention to the potential cannibalization problems from the remanufacturing. In addition, based on Proposition 2, 3 and 4 , we can further conclude that, when the used core collection cost is not pronounced, i.e., $k<k_{1}$, compared to remarketing remanufactured products, collecting used cores may create a "lose-lose-lose" outcomes for the OEM, 3PR, and the overall industry. Therefore, our research suggests that, although collecting used cores is a more efficient way for the OEM to deal with the cannibalization problems, the OEM should not indulge in such strategy.

This research could be extended in the following directions. Firstly, we assumed that the OEM was limited to a linear wholesale price. Although this is common in reality and standard in the literature, it would also be of interest to understand the implications of an OEM uses a more complex pricing mechanism. Second, we assumed that all remanufactured products were identical; in reality, consumers may exhibit differing preferences for remanufactured products sold by different sellers. We hope this research will open other potentially inter- 
esting avenues of research. Finally, given our focus on sustainability issues, we did not consider certain other factors, including the strategies of leasing and selling, which may have a potentially important role in the remanufacturing of durables.

\section{Conflicts of Interest}

The authors declare no conflicts of interest regarding the publication of this paper.

\section{References}

Agrawal, V., Atasu, A., \& Van Ittersum, K. (2012). Remanufacturing, Third-Party Competition, and Consumers' Perceived Value of New Products. Management Science, 61, 60-72. https://doi.org/10.1287/mnsc.2014.2099

Atasu, A., \& Souza, G. C. (2013). How Does Product Recovery Affect Quality Choice? Production \& Operations Management, 22, 991-1010. https://doi.org/10.1111/j.1937-5956.2011.01290.x

Chai, J., Yan, W., Li, Y., Palmer, M., \& Huang, Q. (2019). Selling Vertically Differentiated Products under One Channel or Two? A Quality Segmentation Model for Differentiated Distribution Channels. Journal of the Operational Research Society, 1-19. https://doi.org/10.1080/01605682.2019.1605469

Channel, T. A. (2017). Caterpillar Remanufacturing Services Forms Strategic Alliance with Land Rover. https://www.theautochannel.com/news/2005/08/04/139416.html

Debo, L. G., Toktay, L. B., \& Van Wassenhove, L. N. (2005). Market Segmentation and Product Technology Selection for Remanufacturable Products. Management Science 51), 1193-1205. https://doi.org/10.1287/mnsc.1050.0369

Debo, L. G., Toktay, L. B., \& Wassenhove, L. N. V. (2010). Joint Life-Cycle Dynamics of New and Remanufactured Products. Production \& Operations Management, 15, 498-513. https://doi.org/10.1111/j.1937-5956.2006.tb00159.x

Desai, P. S. (2001). Quality Segmentation in Spatial Markets: When Does Cannibalization Affect Product Line Design? Marketing Science, 20, 265-283. https://doi.org/10.1287/mksc.20.3.265.9767

Ferguson, M. E., \& Toktay, L. B. (2006). The Effect of Competition on Recovery Strategies. Production and Operations Management, 15, 351-368. https://doi.org/10.1111/j.1937-5956.2006.tb00250.x

Giutini, R., \& Gaudette, K. (2003). Remanufacturing: The Next Great Opportunity for Boosting US Productivity. Business Horizons, 46, 41-48.

https://doi.org/10.1016/S0007-6813(03)00087-9

Guide Jr., V. D. R., \& Li, J. (2010). The Potential for Cannibalization of New Products Sales by Remanufactured Products. Decision Sciences, 41, 547-572. https://doi.org/10.1111/j.1540-5915.2010.00280.x

Hauser, W. M., \& Lund, R. T. (2008). The Remanufacturing Industry: Anatomy of a Giant: a View of Remanufacturing in America Based on a Comprehensive Survey across the Industry. Dept. of Manufacturing Engineering.

http://www.bu.edu/reman/

Karakayali, I., Emir-Farinas, H., \& Akcali, E. (2007). An Analysis of Decentralized Collection and Processing of End-of-Life Products. Journal of Operations Management, 25, 
1161-1183. https://doi.org/10.1016/j.jom.2007.01.017

Kotler, P., \& Keller, K. L. (2012). Marketing Management (14th Edition). London: Pearson Education.

Majumder, P., \& Groenevelt, H. (2001). Competition in Remanufacturing. Production and Operations Management, 10, 125-141. https://doi.org/10.1111/j.1937-5956.2001.tb00074.x

Marion, J. (2004). Sun Under Fire for Fixing Solaris OS Costs to Reduce Competition in Used Sun Market. http://www.sparcproductdirectory.com/view56.html

Örsdemir, A., Kemahl, E., lu-Ziya, X. X. F., \& Parlaktürk, A. K. (2014). Competitive Quality Choice and Remanufacturing. Production \& Operations Management, 23, 48-64. https://doi.org/10.1111/poms.12040

Savaskan, R. C., Bhattacharya, S., Wassenhove, V., \& Luk, N. (2004). Closed-Loop Supply Chain Models with Product Remanufacturing. Management Science, 50, 239-252. https://doi.org/10.1287/mnsc.1030.0186

Subramanian, R., \& Subramanyam, R. (2013). Key Factors in the Market for Remanufactured Products. Manufacturing \& Service Operations Management, 14, 315-326. https://doi.org/10.1287/msom.1110.0368

Wang, L., Cai, G., Tsay, A. A., \& Vakharia, A. J. (2017). Design of the Reverse Channel for Remanufacturing: Must Profit-Maximization Harm the Environment? Production and Operations Management, 26, 1585-1603. https://doi.org/10.1111/poms.12709

Xiong, Y., Zhou, Y., Li, G., Chan, H. K., \& Xiong, Z. (2013). Don't Forget Your Supplier When Remanufacturing. European Journal of Operational Research, 230, 15-25. https://doi.org/10.1016/j.ejor.2013.03.034

Yan, W., Xiong, Y., Xiong, Z., \& Guo, N. (2015). Bricks vs. Clicks: Which Is Better for Marketing Remanufactured Products? European Journal of Operational Research, 242, 434-444. https://doi.org/10.1016/j.ejor.2014.10.023

Zou, Z.-B., Wang, J.-J., Deng, G.-S., \& Chen, H. (2016). Third-Party Remanufacturing Mode Selection: Outsourcing or Authorization? Transportation Research Part E: Logistics and Transportation Review, 87, 1-19. https://doi.org/10.1016/j.tre.2015.12.008 